\title{
Leitura oral: uma variável facilitadora de compreesão
}

\section{Oral Reading: a variable that facilitates comprehension}

\author{
Márcia Regina Melchior Landim ${ }^{1}$ \\ Onici Claro Flôres ${ }^{2}$
}

DOI: $10.28998 / 2317-9945.2019$ n63p23-36

\section{Resumo}

Neste relato de pesquisa, leitura e compreensão leitora são consideradas duas atividades cognitivas distintas, não redutiveis nem idênticas, fundamentando-se tal posição em pesquisas neurocientificas que comprovaram que ler, em sentido estrito, é decodificar (DEHAENE, 2007, 2012; MORAIS, 2014; SCLIARCABRAL, 2009, 2013), atestando esses estudos, também, que decodificar não implica compreender (NATION, 2013). Pode-se ler o texto escrito de dois modos: silenciosamente ou em voz alta, sendo necessário considerar, ainda, embora não seja esta objeto do presente estudo, a leitura de imagens (KRESS \& van LEEUWEN, 1996; MAYER, 2001). No Brasil, entre as duas modalidades de leitura da escrita, a mais praticada é a silenciosa. Hoje, contudo, os problemas de leitura - interpretação e compreensão - entre estudantes de todos os niveis (do fundamental ao universitário), evidenciados nas avaliações de leitura - Prova Brasil, Prova ANA, SAEB, PISA - levaram a que a leitura em voz alta e sua associação com a compreensão voltasse a ser investigada. Em vista disso, no primeiro semestre de 2016, propôs-se um estudo exploratório enfocando uma prática de leitura oral, para verificar quais as possiveis dificuldades evidenciadas em um grupo de acadêmicos de letras de uma IES do RS e analisar se pareciam configurar a possibilidade de um distúrbio cerebral ou se apenas indicavam falta de prática de leitura, para fins acadêmicos. Os sujeitos foram expostos à leitura silenciosa, produção de paráfrase, leitura em voz alta e gravação da leitura, seguida de análise. O objetivo foi levar os participantes a monitorar o desempenho do grupo por meio de três critérios: dicção, ritmo e entonação, como proposto por Poersch e Muneroli (1993). Os resultados do trabalho evidenciaram que a leitura oral pode ser uma prática produtiva e eficaz, tendo sua realização promovido envolvimento com a atividade e melhorado a performance dos acadêmicos participantes.

Palavras-chave: Leitura silenciosa. Leitura oral. Interpretação e compreensão

\begin{abstract}
In this research report reading and reading comprehension are understood as distinct cognitive activities, which are non-reducible and non-identical, according to neuroscientific studies that have proved that reading means, in a strict sense, decoding (DEHAENE, 2007, 2012; MORAIS, 2014; SCLIAR-CABRAL, 2009, 2013), and decoding, also according to these studies, does not imply understanding (NATION, 2013). There are two ways of reading the written text: silently, out loud, and also - although it is not within the scope of this study - the possibility of reading images (KRESS \& van LEEUWEN, 1996; MAYER, 2001). In Brazil, the most practiced modality is the silent one. Nowadays, however, the issues related to reading interpretation and comprehension, which involve students at all levels - from elementary to bigher education - evidenced in reading assessments - Prova Brasil, Prova ANA, SAEB, PISA - renewed the interest in the research on reading aloud and its association with comprehension. With that in mind, in the first semester of 2016, it was conducted a study focusing on the oral reading practice, in order to verify the possible difficulties face by a group of undergraduate languages students from a bigher education institution of
\end{abstract}

\footnotetext{
${ }^{1}$ Doutoranda e mestra em Letras pela Universidade de Santa Cruz do Sul.

${ }^{2}$ Doutora em Letras pela Universidade de Santa Cruz do Sul.
} 
Rio Grande do Sul and to analyze if they seemed have any brain disorder or if they only indicated lack of reading practice for academic purposes. The subjects were exposed to silent reading, paraphrase production, reading aloud and recording the reading, followed by analysis. The objective was to monitor their performance through the following criteria: diction, rhythm, and intonation, as proposed by Poersch e Muneroli (1993). The results showed that oral reading can be a productive and efficient practice, since it has improved the engagement and the performance of the participating students regarding the reading activity.

Keywords: Silent reading. Oral reading. Interpretation and comprehension

Recebido em: 24/01/2019.

Aceito em: 30/03/2019.

\section{Introdução}

A atividade de leitura do texto escrito pode se realizar de forma silenciosa ou oral e, ainda que ler não implique necessariamente compreender, ambas as modalidades de leitura exigem compreender, pois ler sem compreender é improdutivo para a maioria dos fins sociais que demandam leitura (MORAIS, 1996). Assim, em função da exigência de compreensão, é relevante ressaltar que, em sentido estrito, ler é decodificar, e decodificar não é compreender, apesar de muitos alfabetizadores, ainda hoje, acreditarem que sim. O problema é que a expressão "ler bem", utilizada de modo genérico, indiferenciado, tem gerado muita confusão e ocasionado dificuldades interpretativas entre os professores do Ensino Básico, pois tanto pode indicar decodificar com rapidez quanto ler com entendimento. $O$ fato, porém, é que o leitor pode decodificar bem sem compreender o que leu (NATION, 2013). Essa possibilidade exige que o professor distinga decifrado de compreendido, preocupando-se inicialmente com a mecanização do processo de decodificação do que é lido, para, a seguir, orientar a atividade de modo que o aluno reflita sobre o sentido do que lê.

Entre as modalidades de leitura aqui consideradas, a mais presente no meio acadêmico/escolar brasileiro é a modalidade silenciosa, tanto em sala de aula quanto em ambientes sociais onde a leitura comumente é praticada, tais como bibliotecas públicas e escolares. A constância dessa presença em sala de aula talvez possa ser explicada pela rejeição à leitura oral de parte dos seguidores do escolanovismo, nos anos 1950 e 1960 (YRIGOYEN, 2003). Em vista desse precedente histórico, interessa discutir em mais detalhes o porquê do descrédito à leitura oral como atividade educativa no país, sobretudo, no período referido, o qual, no entanto, ainda se reflete no presente, mesmo que de forma mais atenuada.

Presumivelmente, foram as críticas acirradas à atitude autoritária dos professores e à exigência de exposição do leitor iniciante aos colegas que acabaram por promover o expurgo quase total da leitura em voz alta das salas de aula do país, devendo-se as críticas emitidas, então, a pesquisadores que recomendavam incrementar a leitura silenciosa e atribuir menos ênfase ao magister dixit. Na verdade, há que reconhecer que a ação desqualificadora deflagrada não foi desmotivada, pois questionava a hegemonia da modalidade oral de leitura no meio social e escolar brasileiro. Em decorrência, só agora, dados os problemas de interpretação e compreensão leitora ora existentes entre estudantes de todos os níveis de ensino, passou a ser cogitada a retomada dos estudos sobre leitura em voz alta e a possibilidade de averiguar se ela podia associar-se à compreensão leitora, como proposto por Poersch e Muneroli (1993). 
Nesse sentido, o presente estudo problematiza os reflexos/efeitos da leitura silenciosa, em sujeitos que agora estão no ensino superior, por meio de uma prática de leitura oral, em que se analisa a dicção, o ritmo e a entonação. A proposta é verificar dificuldades e analisar se estas podem se configurar como um distúrbio cerebral ou se apenas indicam falta de prática de leitura. Como metodologia, utiliza-se a exposição dos sujeitos à leitura silenciosa, a produção de paráfrase, a leitura em voz alta e gravação da leitura, seguida de análise pelos próprios sujeitos.

Para aprofundar a discussão sobre o tema em foco, abordam-se também as relações entre falar e ler, pois, ainda que ler se vincule à fala, a leitura não é uma habilidade humana natural, como falar.

\section{Fala x leitura}

De fato, todos os indivíduos falam sua língua mãe, a não ser que tenham algum problema perceptivo, físico ou psicológico, sendo a fala um continuum de sons linguísticos distintivos que a criança vai internalizando, pelo menos a partir de seu nascimento. Já a leitura demanda conhecer e manejar a escrita que é um continuum de letras, organizado, no caso brasileiro, segundo o sistema alfabético utilizado (MORAIS, 2014). Assim, se falar e ler são habilidades linguísticas diferentes, uma natural e a outra cultural, esta última envolvendo o aprendizado dos símbolos gráficos, faz-se necessário, além de distingui-las, considerar os vínculos existentes entre ambas habilidades linguísticas em foco, uma vez que mantêm entre si relações de influência mútua, até porque a fala é um dos fundamentos do aprendizado da leitura no sistema de escrita do português. Neste, aprender a ler não implica adquirir um novo sistema linguístico, mas sim aprender um novo sistema de sinais, já que a diferença fundamental entre a modalidade oral e a escrita da língua está no meio físico condutor da mensagem: os símbolos vocais ou os símbolos gráficos (MORAIS et al., 1979; MORAIS, 1996).

Assim, tendo em vista o sistema de escrita utilizado, a relação entre fala e leitura é estabelecida através da escrita, e a transferência do meio sonoro (já conhecido) para o meio visual (desconhecido) constitui a primeira fase do processo de aprendizagem da leitura, implicando um conjunto de regras diferentes das que levam o indivíduo a escrever. Essas regras são mais simples do que as da escrita por serem regras de reconhecimento, uma vez que leitura e percepção dos sons da fala são atividades paralelas, ambas integrando o processo de decodificação. Em síntese: o ouvinte decodifica os símbolos do sistema fonológico; e o leitor, os símbolos do sistema ortográfico (MORAIS, 2014).

Em vista disso, os professores de pré-escola e os alfabetizadores precisam observar com atenção o modo como lidam seus alunos com a relação fala/leitura/escrita na fase de transferência do oral para o escrito, isto é, como se saem no período de transposição do conhecimento da modalidade oral da língua para o da modalidade escrita, analisando com bastante atenção e cuidado seus progressos ou recuos. Esse cuidado é indispensável porque, caso o aprendizado da leitura não tenha se consolidado, aprender a escrever pode se tornar uma tarefa bem mais complicada do que já é, usualmente.

Desse modo, as ponderações constantes nos parágrafos precedentes buscam deixar claro que é preciso ler com compreensão, para escrever com autonomia. Se a aprendizagem da leitura apresentar muitas falhas, o aprendizado da escrita vai se tornar mais difícil do que já é. Em suma, o aprendizado da leitura demanda longos anos de esforço, envolvendo o 
desenvolvimento da consciência linguística, em vários níveis - fonológico, morfológico, sintático, semântico, pragmático e textual, da mesma forma que a escrita (PINTO, 1994, 2010).

A partir do exposto, pode-se aquilatar melhor a importância de tomar conhecimento da concepção de leitura da população brasileira dos anos 1950 até os anos 1990, período em que grande número de professores alfabetizadores, e, de modo geral, a população leiga, tinha como certo que o ato de decodificar era sinônimo de ler com compreensão, perdurando essa crença, entre boa parte da população, até a atualidade. Estudos mais recentes (DEHAENE, 2007, 2012; SCLIAR-CABRAL, 2009, 2013; MORAIS, 1996, 2014), no entanto, comprovaram tanto a imprescindibilidade da decodificação quanto sua limitação. Ou seja, a decodificação foi reconhecida como uma etapa indispensável do aprendizado da leitura, porém foi constatado, também, não ser ela a única habilidade a ser considerada, indicando ser urgente uma revisão conceitual de parte dos professores. Certamente, habilitar o leitor a decodificar, ou seja, a fazer a transformação grafema/fonema e acessar o código linguístico é fundamental, mas não é de modo algum suficiente, nem encerra o aprendizado da leitura, não garantindo nem compreensão nem leitura autônoma.

A conclusão a que chegaram os pesquisadores da ciência da leitura, como referido no parágrafo anterior, embasou-se, sobretudo, em estudos neurocientíficos (DEHAENE, 2007, 2009, 2012), evidenciando esses estudos, também, que a atividade de decodificar precisa ser praticada intensiva e extensivamente. Ou seja, a mecanização do processo é necessária, segundo afirma Dehaene (2012), porque apenas essa mecanização do modus operandi do decifrado pode dispensar o leitor de se concentrar exclusivamente nele. Em decorrência, quanto mais praticar o leitor, quanto mais vezes exercitar-se, tanto melhor e mais rápido decodificará, liberando sua mente para a compreensão leitora. Em suma, os investigadores consideram que, ao dispensar a mente de focalizar seus recursos cognitivos na decodificação, o leitor passa a fazer menor número de fixações durante os movimentos sacádicos, o que implica maior concentração em compreender do que em decodificar (NATION, 2013).

Por outro lado, interpretar e compreender (DASCAL, 2006) são dois processos cognitivos complexos, distintos e complementares. No que diz respeito à compreensão, a ela o investigador não tem acesso direto, pois se processa no cérebro de cada leitor, por isso os resultados dos testes que o pesquisador utiliza, sejam eles quais forem, são analisados e, por fim, interpretados. Assim, em decorrência do processamento não captável da compreensão leitora de forma direta - pelo menos até o momento - e tendo em vista a necessidade de conhecê-lo melhor, alguns investigadores passaram a enfocar detalhes mais específicos do processamento cognitivo mais geral da atividade leitora, para apreender de forma indireta o que acontece na mente do leitor, quando ele lê e compreende o que leu.

Nation (2013), por exemplo, concluiu ser possível que bons decodificadores não compreendam o que foi lido por não produzirem inferências, ou seja, por não conseguirem ultrapassar os limites da explicitude textual. O estudo de Nation (2013) evidenciou o fato de que ler com compreensão exige do leitor uma ampla ativação cognitiva que envolve os sentidos, a percepção, a atenção, a associação, a memória, o raciocínio, a imaginação, o pensamento e a capacidade de decodificação.

Além da ampla mobilização cognitiva requerida, o leitor precisa ainda familiarizar-se com aspectos linguísticos diversos - fonológicos, morfológicos, sintáticos, semânticos - bem como atentar para o contexto situacional, relacionando texto e contexto (pragmática). Em suma, as habilidades de leitura ultrapassam em muito a mera decodificação (PINTO, 2010). Todavia, é importante frisar que, se as habilidades de leitura ultrapassam a decodificação, 
dela não prescindem em hipótese alguma, sobretudo, nas línguas que utilizam o sistema de escrita alfabético (GRABE, 2009).

\section{Qual a distinção entre leitura proficiente e leitura não proficiente?}

Em primeiro lugar, é preciso dizer que os leitores, de modo geral, não são igualmente proficientes em leitura oral e silenciosa, nem na leitura de todo e qualquer texto de qualquer gênero e tipo. Tal observação também diz respeito aos professores, que têm limitações e possibilidades, da mesma maneira que todos os demais leitores.

No meio escolar e acadêmico, por outro lado, não existe a necessária explicitude sobre como e o que avaliar em leitura. De que leitura se está falando? Conforme estudo de Cunha et al. (2009), que investigou a produção científica voltada à avaliação da leitura no contexto escolar nos anos de 1996 a 2005, os dados revelaram a necessidade de pesquisas voltadas à avaliação da leitura, principalmente no que diz respeito à qualidade dos instrumentos. Muitos estudos foram vagos e não esclareceram a que modalidade de leitura se referiam. E assim, persiste certa indefinição, como se fosse possível evidenciar compreensão apenas por meio de leitura silenciosa. Talvez em decorrência desse estado de coisas, os professores das escolas continuem propondo apenas, ou sobretudo, leitura silenciosa.

Quanto ao ensino de leitura, propriamente, o que se sabe é que no contexto brasileiro, os professores do Ensino Fundamental e Médio não se dedicam a ensinar a ler, a não ser nos três anos iniciais, período da alfabetização, mesmo que os alunos demonstrem necessitar desse aprendizado. De hábito, é feita a proposição de uma atividade de leitura silenciosa e, após, entregues aos alunos perguntas sobre o texto lido; ou, então, o professor solicita a produção de um resumo ou, simplesmente, o professor entrega um texto aos alunos ou indica uma página determinada do livro didático e pede que a leiam e formulem - por escrito - sua opinião sobre o que foi lido. Usualmente, não são debatidas as várias interpretações nem são destacados aspectos conteudísticos interessantes ou discutíveis dos textos, muito menos são feitas comparações entre as interpretações, para verificar, por exemplo, o que levou o aluno $\mathrm{X}$ a interpretar de tal forma. Além disso, há pouco ou nenhum investimento na leitura oral, que não é uma atividade tida como indicadora de compreensão.

O procedimento pedagógico ideal, contudo, seria praticar as duas modalidades de leitura, dando visibilidade à diferença dos critérios avaliativos utilizados em cada caso. Seria recomendável também não transformar as atividades leitoras em meros testes de proficiência sem qualquer retorno, explicação, sugestão ou incentivo. A falta de envolvimento do professor com a leitura, em si e por si mesma, sua despreocupação com o seu ensino e a supervalorização do resultado obtido ou, simplesmente, o desinteresse evidenciado, inviabilizam ou dificultam muito o envolvimento dos alunos. Em suma, tanto é prejudicial punir ou exigir demais, como acontecia quando os professores solicitavam apenas leitura oral e consideravam sua interpretação como a única "certa", quanto não dar importância alguma à leitura, seja oral seja silenciosa, situação atual, pois ambos modos de proceder esvaziam o dialogismo propiciado pela atividade. 


\section{Por que ler com compreensão é imprescindível?}

Ler com compreensão é indispensável, porque, atualmente, nas sociedades letradas como a brasileira, vive-se imerso em textos. Não há como escapar dessa realidade, se a pessoa quiser participar com mais efetividade da vida social. Em vista disso, explicita-se o conceito de leitura assumido pelo presente estudo, que a entende como um processo ativo de interação entre autor, texto e leitor (FLÔRES, 2007; KLEIMAN, 2004). Nele, parte da informação é lida e outra parte é inferida. A inferenciação se processa por meio da ativação dos conhecimentos prévios armazenados na memória de longo termo do leitor, que depois de decodificar consegue deslocar seus recursos cognitivos para a compreensão textual. A compreensão leitora demanda, pois, a formulação de inferências que auxiliam o leitor a entender o que está sendo lido. Em síntese, as pesquisas indicam que compreender é um nível mais complexo do processamento da informação, mobilizando mais profunda e distribuidamente funções cognitivas, além daquelas utilizadas no ato de decodificar (NATION, 2013).

A leitura proficiente ancora-se em processos que demandam fluência, automatismo, precisão e rapidez, no reconhecimento das palavras e na compreensão do material lido. O reconhecimento de palavras (acesso ao léxico mental), em um sistema de escrita alfabético pode ocorrer de duas maneiras:

1) Por meio de um processo visual direto (rota lexical) ou

2) Por meio de um processo indireto, que implica mediação fonológica. Esse é o modelo de leitura de dupla-rota (ELLIS, 1995; HILLIS; CARAMAZZA, 1992).

Especificamente, a Rota Fonológica, ou seja, o processo indireto de ler e escrever, exige a mediação ortografia/fonologia. Por meio dela, o leitor faz a conversão grafema/fonema (decodificação) - para ler - ou fonema/grafema (recodificação) - para escrever. $O$ vaivém do processo possibilita a escansão das palavras, através do pareamento entre letra (grafema) > som linguístico regular (fone/fonema), ou vice-versa, sendo altamente requisitado por leitores inexperientes, e, ainda, por leitores experientes, quando desconhecem o assunto ou o vocabulário do texto.

Quanto à Rota Lexical, processo visual direto, em geral, utilizada por leitores hábeis, ativam-se as representações de palavras familiares armazenadas em um léxico de entrada visual, que franqueia o acesso ao significado (SEYMOUR, 1987). Contudo, mesmo leitores fluentes recorrem às duas rotas, como já referido antes, por isso todos os leitores têm a possibilidade de usar uma ou outra das rotas a qualquer momento de sua leitura, se assim o desejarem ou necessitarem.

De outra parte, há que salientar que o valor conferido a uma ou outra das modalidades de leitura depende do número de investigações em andamento no período ou, então, à presença mais constante de uma das modalidades na vida social das pessoas de uma dada comunidade. Assim, é a diferença de uso que acaba mostrando qual a concepção de leitura mais em voga em cada época histórica. Desse modo, considerando-se aqui o critério "investigações realizadas" fica evidente que a partir dos anos 70 do século XX, as pesquisas passaram a concentrar seu interesse na leitura silenciosa. O fato é depreensível a partir do levantamento das pesquisas feitas no período. Esse fato se deveu, segundo afirmam alguns investigadores (CHARTIER, 1988), a uma mudança de perspectiva nos fundamentos embasadores dos estudos da área, que antes disso valorizavam, de modo exclusivo, a leitura oral e o magister dixit interpretativo. Ao se deslocar a posição do pêndulo teórico de uma para 
outra extremidade, ou seja, da valorização da leitura oral para o da leitura silenciosa, os testes usados passaram a ser a parafrasagem ou respostas a perguntas sobre compreensão leitora com base na leitura silenciosa, seja de um texto, seja de sentenças ou de palavras, conforme se tratassem de leitores iniciantes ou mais experientes (CAPOVILLA; CAPOVILLA, 2002, 2003, 2004; LEFFA, 1996).

A situação atual, porém, mostra outro cenário e problemas distintos daqueles existentes à época do movimento escolanovista. De fato, hoje os pesquisadores estão voltando, novamente, suas atenções para a leitura oral porque os problemas de leitura ou de sua falta avolumaram-se, agravando-se muito entre o final do século XX e o início do século XXI. No momento, tudo indica ser necessário combinar - no ensino básico e na academia - atividades de leitura oral e silenciosa, bem como de leituras multimodais (MAYER, 2001; KRESS; van LEEUWEN, 1996), tema muito pouco considerado pelos professores, para, só assim, se poder fazer frente às dificuldades que se apresentam. De fato, a preferência do leitor pode ser por uma ou outra modalidade, mas o que aqui se pondera é que talvez as habilidades de interpretação e de compreensão, bem como a própria habilidade de leitura (decodificação) se desenvolvam e ampliem com base nas duas modalidades, bem como na leitura de imagens, não se esgotando em apenas uma delas, pelo menos não de modo absoluto, já que as habilidades leitoras envolvidas em cada caso não são idênticas.

\section{Leitura \& Ensino: leitura oral e leitura silenciosa e sua contribuição para o aprimoramento da competência leitora}

Em termos históricos, a leitura em voz alta tem mais tradição, tendo sido a única atividade leitora cultivada, no mundo inteiro, até a Idade Média. Nesse período, ler silenciosamente não era uma pretensão sequer cogitável para a maioria das pessoas, devendose o fato a diversos fatores, dentre eles o da inexistência de material escrito acessível. De acordo com Chartier (1988), apenas por volta do século XII a leitura silenciosa (visual) foi introduzida nas escolas e nas universidades. Ler silenciosamente, no entanto, demandava esforço considerável, uma vez que a escrita da época não utilizava as fronteiras de palavras, não as separando entre si. Na prática, diz Chartier (1988), para entender o que estava sendo lido, o leitor tinha de vocalizar, isto é, ler em voz alta. Por outro lado, talvez não houvesse tantas pessoas interessadas em aprender a ler, visto que a leitura não era uma necessidade premente para a população em geral. Muitas transações, inclusive jurídicas, eram resolvidas com base na palavra dada e "no fio de bigode".

Assim, de modo geral e por muitos séculos, a leitura em voz alta foi a única opção de leitura existente, sendo programada para encontros sociais diversos, os quais reuniam indivíduos alfabetizados, analfabetos e semialfabetizados. No período, havia um número mínimo de textos escritos disponíveis e o público alfabetizado era inexpressivo. Contudo, como as reuniões sociais agregavam grande número de participantes, muitos deles se tornaram leitores "de ouvido", seja de folhetins, da Bíblia, de poemas, de folhetos de cordel, de romances, de cartas, ou de jornais. No Brasil, inclusive em ambientes considerados mais ilustrados, eram comuns reuniões sociais em que um dos convidados se encarregava de ler em voz alta, recitar poemas ou contar histórias, complementando-se o sarau com audições musicais, conversas sobre temas diversos e conluios políticos. O cultivo da leitura oralizada era tão forte por aqui, que Antonio Candido (1965) afirmou que, mesmo entre as elites, na primeira metade do século XX, havia um público maior de "leitores ouvintes" do que de leitores, propriamente. Nesse período, a oralidade predominava como modo de comunicação em espaços sociais, como igrejas, repartições públicas e escolas. 
Com relação à época a que se reporta este estudo, a partir da metade do século XX, as práticas escolares cotidianas, pelo visto, restringiam-se à leitura em voz alta. A partir desse período, todavia, a leitura oral foi desaconselhada pelo movimento da Escola Nova, que era favorável à leitura silenciosa, o que fez com que os professores abandonassem a leitura oral, de modo quase irrestrito. $\mathrm{O}$ tudo ou nada assumido pela escola e pelos professores foi radical (SAVIANI, 2007; INEP, 1944).

Vale destacar que, no período em que a leitura oral predominou, acreditava-se que, além de exercitar a própria leitura (aprimorando-a) e de fornecer critérios para que o professor avaliasse a dicção, a impostação da vOz, a entonação, a pontuação e a fluência, sua prática influenciava o modo de os alunos se expressarem oralmente, numa época em que falar bem era tão ou mais importante do que escrever bem. $\mathrm{O}$ aspecto mais negativo desse período era que ler em voz alta permitia, também, que o professor controlasse o sentido da leitura, tendo o privilégio de "impor sua interpretação", considerada a única correta ou aceitável.

Deixando os excessos de lado, é interessante observar que, no período, a escola possibilitou a formação de grande número de leitores que, embevecidos com a voz do(a) professor(a), se transportavam para outros mundos, imaginavam, "viajavam" sem interferência de ninguém, embalados por sua voz. Com a disseminação dos preceitos da Escola Nova, porém, os professores atuantes nas redes de ensino passaram a evitar a leitura em voz alta, exigida até então de parte dos alunos e também eles, professores, deixaram de fazê-lo, a fim de não direcionar a "interpretação".

Atualmente, todavia, a leitura em voz alta, bem como a leitura multimodal podem se transformar em importantes instrumentos de aproximação da escrita, tanto por parte de crianças quanto de adultos de qualquer nível de ensino, permitindo-lhes apreender a estrutura e algumas das características dos textos escritos, com naturalidade, por meio da recepção leitora e da observação dos detalhes imagéticos que aparecem nos mais diversos textos, complementando, reiterando ou acrescentando informações ao que é lido.

Além do mais, do ponto de vista psicolinguístico, a prática da leitura oral exercita os músculos da fonação e da articulação e mecaniza os movimentos respiratórios necessários para produzir os sons linguísticos da língua em que está escrito o texto. De outra parte, possibilita registrar com maior eficácia e durabilidade o que se aprendeu ouvindo, do que o que se aprendeu lendo pessoalmente o texto (MELLI, 2011). Isto é, alguns estudiosos acreditam que a memória fixa mais fortemente a palavra ouvida do que a lida. Outro beneficio da leitura em voz alta é que ela ensina a dosar a voz, adequando-a ao espaço e ao número de ouvintes do local em que está sendo feita.

Em épocas pregressas, ou seja, dos anos 50 até os anos 90, os autores se preocupavam em recomendar procedimentos para ler adequadamente em voz alta, dada a frequência dessa prática leitora. Por exemplo, Bueno (1966) recomendava controlar a respiração. Outros aspectos psicofísicos importantes são, de acordo com ele, os seguintes:

1) Manter a posição do tórax reta e desimpedida;

2) Ter em mente que os fonemas do português são produzidos durante a expiração, portanto nunca pronunciar um fonema que seja, quando estiver inspirando. Isso pode causar desconforto e tosse;

3) Não respirar no meio de uma palavra ou frase para não alterar a prosódia da palavra ou a cadência frasal; 
4) Não esperar que os pulmões se esvaziem de ar para enchê-los, durante a leitura, porque isso apressaria o seu ritmo, desnecessariamente. Não é preciso "correr" para acabar a tarefa;

5) Para não se atrapalhar com a respiração, observar as vogais, elas permitem maior ou menor extensão de emissão por serem sonoras, dando condições de alongar ou abreviar o fluxo da atividade leitora;

6) Prestar atenção ao conector (conjunção), ele indica quando vai ocorrer a passagem de um membro da frase para outro, ou de uma oração para a seguinte, permitindo respirar no decurso da leitura (BUENO, 1966).

É claro que tudo isso é importante, mas é a prática que melhora o desempenho, portanto é imprescindível ler mais vezes em voz alta para beneficiar-se com o exercício. A maior contribuição da leitura em voz alta, entretanto, é que ela, em geral, parece propiciar o despertar do gosto pela leitura, permitindo que a imaginação do ouvinte flutue ao sabor das palavras do texto, levando-o a querer ler por conta própria.

\section{As pré-condições para o aprendizado da leitura}

Não sendo a leitura, seja silenciosa seja oral, uma habilidade humana natural como falar ou andar, demanda-se o preenchimento de certos pré-requisitos, já que não basta ter um desenvolvimento normal para que a pessoa aprenda a ler. Assim, é importante destacar que, ainda que a leitura faça parte dos estudos da linguagem, não é adquirida naturalmente, pois seu aprendizado não funciona de modo automático (sem reflexão), exigindo consciência linguística em vários níveis (PINTO, 1994).

A primeira das pré-condições existentes diz respeito ao leitor e ao seu entendimento de como proceder para fazer a leitura, relacionando grafema/fonema (consciência fonológica). Assim sendo, de modo usual, para ler nas línguas alfabéticas como o português, cada leitor tem de descobrir qual é o princípio que orienta a escrita, relacionando grafema/fonema.

Da não descoberta do princípio fonológico pelo leitor iniciante resulta a possibilidade de a leitura tornar-se um problema de aprendizagem, que, como tal, pode ter causas diversas. Caso, porém, decorra do funcionamento alterado do cérebro do indivíduo, torna-se um caso clínico. Tendo em vista essa possibilidade, as pesquisas sobre leitura da área da psicologia cognitiva, principalmente, têm demostrado certa tendência a considerar as dificuldades de leitura dos alunos - tanto de crianças iniciantes na escola quanto de jovens e adultos -, como atestando algum grau de dislexia (ALVES et al., 2014). Porém, há que ter cautela, pois a dislexia não é facilmente diagnosticável, havendo muita polêmica acerca de sua etiologia (LÓPEZ-ESCRIBANO, 2007).

Dessa maneira, dados os problemas para diagnosticar a dislexia e as controvérsias relativas à caracterização dessa disfunção, optou-se por fazer um estudo exploratório para verificar quais as possíveis dificuldades evidenciadas em um grupo de acadêmicos de Letras de uma IES do RS, no $1^{\circ}$ semestre de 2016, e analisar se pareciam configurar a possibilidade de um distúrbio cerebral ou se apenas indicavam falta de prática de leitura, para fins acadêmicos.

Esse cuidado pedagógico preliminar embasou-se na constatação de que medidas de ordem geral, aplicadas sem critérios delimitadores, costumam ser ineficazes. Além disso, a 
precaução fundamenta-se nas discussões a respeito de leitura na área da linguística, pois algumas das dificuldades consideradas nos testes propostos pela psicologia cognitiva para diagnosticar as perturbações de leitura em português são contestadas por investigadores da área (CAGLIARI, 1989, 1990, 2002), enquanto indicadoras de transtornos cerebrais.

Em suma, considerou-se mais adequado investir na busca de alguma estratégia de investigação que não encobrisse os problemas sociais, transformando-os em um problema cerebral de um dado indivíduo. De fato, aprende-se a ler, lendo, e a escrever, escrevendo. E o aprendizado não acaba, perdurando ao longo de toda a vida (STANOVICH, 1986).

\section{O estudo feito: procedimentos e resultados}

Os participantes da investigação aqui relatada foram treze (13) alunos do curso de Letras, no primeiro semestre de 2016. De início, foi proposta a leitura silenciosa de uma crônica, lida durante a aula, e em seguida a produção de uma paráfrase. $\mathrm{Na}$ aula seguinte, fezse a proposta de leitura oral da paráfrase, sendo cada leitura gravada de modo a permitir análise posterior. Para a observação, foram utilizados três critérios: dicção, ritmo e entonação. $\mathrm{O}$ estudo foi exploratório e a professora e os alunos da turma fizeram a avaliação de cada leitura (on-line e gravada), comentando os desvios observados quanto aos critérios selecionados:

\section{I - O critério dição foi avaliado quanto à:}

1) Clareza, ou seja, emissão nítida das palavras do texto com fraseamento adequado, por exemplo, não alterando a pronúncia de uma frase interrogativa por uma declarativa;

2) Omissão de fonemas, sílabas ou palavras escritas no texto;

3) Inserçao de fonemas, sílabas ou palavras inexistentes no texto, além de trocar, por exemplo, palavras escritas no texto por sinônimos;

4) Alteração da ordem das sílabas numa palavra lida (camalhaço por calhamaço).

II - O critério ritmo, isto é, a cadência com que foi feita a leitura englobou a análise dos seguintes aspectos:

1) Repetição de palavras e/ou correções de palavras já lidas;

2) Precipitação ou lentidão de leitura;

3) Emissão do texto;

4) Intensidade e duração inadequadas das informações textuais. Este critério considerou a inadequação do acento de palavra ou a má distribuição da informação nova e velha, sobretudo quando as frases eram longas ou não estavam na ordem direta;

5) Pausas inadequadas (omissões, inserções e trocas).

III - O critério entonação ou modulação verificou se o leitor modificava ou não a linha melódica da voz ao longo do texto para dar maior expressividade à leitura, ou seja, registrou se a linha melódica frasal se alterava ou se mantinha sempre igual (alta, quase inaudível, lenta, monocórdia).

A análise das leituras considerou as falhas apontadas pelos ouvintes (grupo de participantes) e pela professora. A junção das duas fontes de observação concluiu que nenhuma das leituras foi impecável, perfeita, pois todos os leitores cometeram algum deslize relacionado, sobretudo, ao ritmo. Nesse critério ocorreram algumas correções de palavras já lidas (sete alunos), precipitação na leitura (três alunos), lentidão exagerada da leitura (um aluno), pausas inadequadas (cinco alunos), troca de acento de palavra (quatro alunos). A 
leitura de dois alunos foi acompanhada com muito interesse por todo grupo de ouvintes que os aplaudiu ao final. As demais leituras foram consideradas boas, pois não apresentaram muitos deslizes (no máximo quatro), ainda que não tivessem sido suficientemente expressivas (leitura com expressividade, performance, ritmo, entonação, dicção, volume, fluência) (OLIVEIRA, 2010) .

Houve uma falha clara quanto ao critério diç̧ão (pronúncia de uma frase interrogativa como declarativa), havendo nesse caso, fraseamento inadequado. Considerou-se, então, que a leitura evidenciara dificuldade de compreensão do leitor, talvez por desatenção. Os demais itens arrolados nesse critério exigem alguma ponderação, pois as omissões de fonemas foram aquelas usuais na fala geral como tomá por tomar; podê por poder e assim por diante. Por outro lado, as inserções de fonemas relacionaram-se ao dialeto social falado pelo aluno - traiz. por traz etc. Importa comentar ainda que dois (2) alunos trocaram palavras do texto por sinônimos, perfeitamente adequados ao cotexto frasal. Esse último dado, referente à troca de palavras do texto em leitura por palavras sinônimas, manifesta-se também em casos relatados por pesquisadores da área da saúde, não havendo até o momento nenhuma explicação definitiva relativamente a esse tipo de ocorrência, segundo afirma Lent (2010).

O trabalho, ainda que apenas exploratório, indicou algumas direções de pesquisa. Em primeiro lugar, confirmou, ainda que não se possa generalizar essa conclusão, dada à exiguidade da amostra, que quem ouve uma boa leitura tem melhor lembrança daquilo que ouviu comparado com a lembrança daquilo que ele próprio leu (MELLI, 2011). Em segundo lugar, a leitura oral tem um componente importante que quase não é comentado - ela é performática - o leitor usa a voz e o corpo para ler, mesmo que não necessariamente faça movimentos amplos.

Quanto ao critério dição, o estudo de Poersch e Muneroli (1993, p. 23) concluiu que "[...] embora constitua um componente da expressividade, está mais relacionada com a recodificação do que com a decodificação". O estudo aqui relatado, contudo, não confirmou tal conclusão, não considerando que a dicção esteja vinculada prioritariamente à experiência de transformação do fonema em grafema (recodificação), pois a concordância verbal alterada pela leitura, por vezes, afeta a identidade referencial e, por conseguinte, a compreensão. De fato, o leitor lê a palavra (que já está contida em sua memória) como a pronuncia, esteja ela escrita do modo que estiver.

Por outro lado, em pesquisas desse tipo, o procedimento usual é propor a atividade de leitura silenciosa do texto para, em seguida, ser solicitada a leitura oral, o que foi feito. Tendo em vista o procedimento usado, que requer a leitura silenciosa apenas uma vez, talvez a variável interveniente que mais tenha afetado o desempenho dos leitores tenha sido a falta de experiência de leitura oral, devendo tal fato ser averiguado mais a fundo. De outra parte, houve um caso de fraseamento inadequado que, de modo claro, indicou falta de compreensão (frase declarativa por interrogativa). A conclusão a que se chegou, então, é a de que é necessário fazer mais pesquisas para saber se, de fato, o critério dicção é um critério fraco, como indicador de compreensão e, também, coletar outras evidências de fraseamento alterado.

Quanto à avaliação de ritmo e entonação, os resultados obtidos corroboraram os resultados de Poersch e Muneroli (1993), visto que esses componentes parecem se relacionar estreitamente à decodificação, vinculando-se, pois, à compreensão. Além disso, foi praticamente inviável separar os fatores entonação, intensidade e duração, já que não se dispunha de instrumentos de análise precisos. 


\section{Considerações finais}

A área de investigação da leitura enfrenta desafios antigos e atuais. Um desafio antigo é o de despertar o gosto pela leitura. Para enfrentá-lo, uma atitude necessária é a de que pais (família) e professores (escola) reúnam esforços para despertar o gosto pela leitura entre crianças e jovens. Outra atitude diz respeito à atuação dos professores, que precisam desautomatizar seus procedimentos de ensino habituais. Para tanto, precisam atualizar-se teoricamente, selecionar textos que se adequem a seu grupo de alunos e produzir perguntas que levem os alunos a refletir, direcionando-lhes a atenção. Este direcionamento é imprescindível para que os alunos possam inferir, atividade que implica relacionar o que já sabem e sentem com o que estão lendo no momento. Esse é o real problema da leitura, pois não basta decodificar, é preciso compreender. Para compreender, no entanto, há que mobilizar os recursos cognitivos existentes, ou seja, para que o leitor não fique passivo, a sua memória de longo termo tem de ser mobilizada, a fim de que seus conhecimentos prévios sejam ativados. Só dessa forma ele pode inferir; sem isso ele apenas repete o que lembra ou emudece.

Além disso, é preciso investir em pesquisas sobre ensino de leitura. Quanto ao ensino, propriamente, os resultados da presente investigação autorizam que se sugira aos professores ler em voz alta para seus alunos e vice-versa, isto é, que os alunos também possam ler para o professor e seus colegas, sem que seja sempre o mesmo aluno a fazê-lo. Outra sugestão é que os professores programem tanto atividades de leitura oral quanto de leitura silenciosa.

A proposta, então, é a de retomar as práticas de leitura oral, sem as exigências avaliativas anteriores, que eram, realmente, inadequadas e intransigentes. Se as exigências anteriormente feitas eram desmesuradas não há, no entanto, razão alguma para excluir as atividades de leitura oral do contexto escolar e acadêmico pois, como se evidenciou no estudo feito, ela coopera para o amadurecimento do leitor, para o incremento e despertar do gosto pela leitura e, também, para o desenvolvimento da competência leitora, pois, conforme já escreveram Poersch e Muneroli (1993, p. 13), a leitura oral é "uma variável facilitadora de compreensão".

\section{Referências}

ALVES, S.; FELIPE, L. A.; PEREIRA, A. P.; SECO, G. M.; PEREIRA, M. Dislexia em Estudantes do Ensino Superior: alguns dados da intervenção no Instituto Politécnico de Leiria/Portugal. Colóquio Internacional Sobre Leitura - Processos de Leitura e Perturbações, 3. Faculdade de Letras - Universidade de Lisboa, 4 e 5 dez. 2014.

BUENO, Silveira. Manual de Califasia, Califonia, Calirritmia, e a Arte de Dizer. 7. ed. São Paulo: Saraiva, 1966.

\section{CAGLIARI, L. C. Alfabetização e linguística. São Paulo: Scipione, 1989.}

CAGLIARI, L. C. Ditados e ditadores - entendidos e entendentes: algumas considerações sobre ditados, cópia e interpretação de texto na escola de primeiro grau. In: TASCA, M. (org.). Desenvolvendo a língua falada e escrita. Porto Alegre: Sagra, 1990.

CAGLIARI, L. C. Análise fonológica: introdução à teoria e à prática, com especial destaque para o modelo fonêmico. Campinas: Mercado de Letras, 2002. 
CANDIDO, A. Literatura e sociedade. São Paulo: Companhia Editorial Nacional, 1965.

CAPOVILLA, A. G. S.; CAPOVILLA, F. C. Otimizando a aquisição da linguagem escrita: comparação entre os métodos fônico e global de alfabetização. Cadernos de

Psicopedagogia, v. 2, n. 3, p. 68-97, 2002.

CAPOVILLA, A. G. S.; CAPOVILLA, F. C. Alfabetização: método fônico. 2. ed. São Paulo: Memnon; Fapesp; CNPq, 2003.

CAPOVILLA, F. C.; CAPOVILLA, A. G. S. Research on the role of phonology, orthography and cognitive skills upon reading, spelling and dyslexia in Brazilian Portuguese. In: SMYTHE, I.; EVERAT'T, J.; SALTER, R. (org.). International book on dyslexia: a cross language comparison and practice guide. London: John Wiley \& Sons, p. 159-172, 2004.

CHARTIER, R. A história cultural entre práticas e representações. Tradução: Maria Manuela Galhardo. Lisboa: Difusão Editorial, 1988.

CUNHA, N. B et al.. Produção científica da avaliação da leitura no contexto escolar. Psico, Porto Alegre, v. 40, n. 1, p. 17-23, jan./mar. 2009.

DASCAL, M. Interpretação e compreensão. São Leopoldo: Unisinos, 2006.

DEHAENE, S. Les neurones de la lecture. Paris: Odile Jacob, 2007.

DEHAENE, S. Reading in the brain - the new science of how we read. New York: Penguin, 2009.

DEHAENE, S. Os neurônios da leitura - como a ciência explica a nossa capacidade de ler. Tradução: Leonor Scliar-Cabral. Porto Alegre: Penso, 2012.

ELLIS, A. W. Leitura, escrita e dislexia: uma análise cognitiva. Porto Alegre: Artes Médicas, 1995.

FLÔRES, O. C. Dualismo em leitura. Moara, Belém, n. 28, p. 58-73, 2007.

GRABE, W. Reading in a second language: moving from theory to practice.

Cambridge: Cambridge University Press, 2009.

HILLIS, A. E.; CARAMAZZA, A. The reading process and its disorders. In:

MARGOLIN, D. I. (org.). Cognitive neuropsychology in clinical practice. New York, Oxford: Oxford University Press, 1992.

INEP. "Manifesto dos Pioneiros da Escola Nova". Revista brasileira de estudos pedagógicos, v. 1, n. 1, jul. 1944. Rio de Janeiro: Instituto Nacional de Estudos Pedagógicos, 1944 - Publicação oficial do Instituto Nacional de Estudos e Pesquisas Educacionais.

KRESS, G.; VAN LEEUWEN, T. Reading Images. The grammar of visual Design. London: Routledge, 1996.

LEFFA, V. Aspectos da leitura: uma perspectiva psicolinguística. Porto Alegre: SagraLuzzatto, 1996.

LENT, R. Cem bilhões de neurônios: conceitos fundamentais da Neurociência. São Paulo: Atheneu, 2010. 
LÓPEZ-ESCRIBANO, C. Contribuciones de la neurociencia al diagnóstico y tratamiento educativo de la dislexia del desarrollo. Revista de Neurologia, v. 44, n. 3, p. 173-180, 2007.

KLEIMAN, A. Texto \& leitor: aspectos cognitivos da leitura. 9. ed. Campinas: Pontes, 2004.

MAYER, R. Multimedia learning. Cambridge: Cambridge University Press, 2001.

MELLI, N. C. de A. Ouvir ou ler? Como se aprende mais? Um estudo em um curso superior de Engenharia. Congresso Internacional de Educação à Distância, 17. 2011. Disponível em: www.abed.org.br/congresso2011/cd/86.pdf. Acesso em: 14 abr. 2019.

MORAIS, J. et al. Does awareness of speech as a sequence of phonemes arise spontaneously? Cognition, n. 7, p. 323-331, 1979.

MORAIS, J. A arte de ler. São Paulo: Unesp, 1996.

MORAIS, J. Alfabetizar para a democracia. Porto Alegre: Penso, 2014.

NATION, K. Dificuldades de compreensão da leitura em crianças. In: SNOWLING, M. J.; HULME, C. (org.). A Ciência da Leitura. Porto Alegre: Penso, 2013, p. 266-283.

OLIVEIRA, E. K. Leitura, voz e performance no ensino de literatura. Signótica, Goiânia, v. 22, n. 2, p. 277-307, jul./dez. 2010.

PINTO, M. da G. L. C. Desenvolvimento e distúrbios da Linguagem. Porto: Porto Editora, 1994.

PINTO, M. da Graça. As bases da leitura: entre a "ciência" da literacia precoce e a "ciência" do jogo. Letras de Hoje, v. 45, n. 3, p. 26-34, 2010.

POERSCH, J. M.; MUNEROLI, A. N. O. O leitor como intérprete das pistas que o escritor insere no texto: a leitura oral expressiva. Letras de Hoje, Porto Alegre, v. 28, n. 4, p. 9-34, 1993.

SAVIANI, D. História das idéias pedagógicas no Brasil. Campinas: Autores Associados, 2007.

SCLIAR-CABRAL, L. Reconhecimento das invariâncias por neurônios reciclados. Signo, Santa Cruz do Sul, v. 37, n. 57, 2009.

SCLIAR-CABRAL, L. Sistema Scliar de Alfabetização - Fundamentos. Florianópolis: Lili, 2013.

SEYMOUR, P. H. K. Individual cognitive analysis of competent and impaired reading.

British Journal of Psychology, n. 78, p. 483-506, 1987.

STANOVICH, K. Matthew effects in reading: some consequences of individual differences in the acquisition of literacy. Reading Research Quarterly, v. XXI, n. 4, p. 360-407, 1986.

YRIGOYEN, V. Práticas de leitura: da oral à silenciosa. Linha D’Água, São Paulo, n. 16, p. 49-60, 2003. 